\title{
EL ENIGMA COMO TÁCTICA INTERPELATIVA EN UN CUENTO DE MAGÓN
}

\author{
María Amoretti Hurtado
}

\begin{abstract}
RESUMEN
Luego de observar la forma específica de la interpelación ideológica en un cuento magoniano, se propone la hipótesis de que la identidad cultural es un acto de connivencia social que se realiza en una gestual lingüística muy similar a aquella forma simple que André Jolles denomina enigma.
\end{abstract}

\begin{abstract}
After looking into the specific ideological questioning in one of Magon's short stories, the following hypothesis is put forth: cultural identity is a social connivence act performed through a linguistic gestual code very similar to the simple form André Jolles calls enigma.
\end{abstract}

En una publicación anterior (1998-2), hicimos un detallado análisis del célebre cuento de Magón titulado "El clis de sol". En ella destacamos sobre todo el significado de este cuento dentro de una época de gestación de la nacionalidad y en la cual esa literatura jugó un papel relevante como constructora de identidad.

En el presente artículo retomamos ese hilo para dedicarnos exclusivamente a las formas de la interpelación ideológica detectables en ese relato, con los siguientes propósitos:

1. Repasar el concepto althusseriano de interpelación y observar el modo en que éste se inserta en una teoría del sujeto cultural, tal y como la propone la escuela sociocrítica montpelleriana.

2. Estudiar la específica forma que adquiere esa interpelación en el relato magoniano.

3. Plantear la hipótesis de que la identidad cultural, como acto de cohesión y afiliación que se realiza en y por la lengua, funciona como un gesto lingüístico al que Jolles denomina enigma.

En su libro Las formas simples, afirma André Jolles que es importante la consideración de la obra literaria no sólo como arte sino también como lengua. Así afirma: 
... la obra artística ya realizada, o la creación artística única e individual de un poeta, constituyen el final y no el comienzo de nuestra investigación. No tomamos la "obra poética" en su realización artística, la tomamos en sus comienzos, es decir, en la lengua (Jolles 1972: 15).

Con una actitud semejante estamos enfrentando nosotros la obra de Magón, pero con una diferencia fundamental: el tomar la obra en sus comienzos es precisamente lo que nos permite explicar su acabado final, su realización artística. Para nosotros, es justamente en el nivel de "lengua" (entendida como se definirá más adelante), en donde habrá de buscarse la motivación social de la estética de la obra y la interpelación cultural o ideológica sobre la que basa su relación comunicativa. Para nosotros, tomar la obra en sus comienzos, "en la lengua" -como dice Jolles-, es tomarla como práctica discursiva y como práctica social. En Sociocrítica el discurso es precisamente el eslabón, la mediación, entre las estructuras de sociedad y las estructuras textuales; de modo que, contrariamente de lo que piensa Jolles, tomar la obra "en sus comienzos", es decir, "en la lengua", para nosotros no significa desestimar su realización poética, sino más bien encontrar en su realización artística las marcas de su socialidad, socialidad que se presenta ahí en forma de lengua, es decir, en forma discursiva. En este artículo, como en otros que sobre este mismo autor hemos ya publicado ${ }^{1}$, nuestro propósito es la indagatoria y diseño de una especie de mitología y epopeya de la identidad a partir del hablar y el actuar que se manifiesta en las formas artísticas de uno de los autores más destacados del período nacionalista costarricense. De esta manera, las sugerencias teóricas de Jolles resultan muy pertinentes para nuestros objetivos y el enigma es precisamente una de esas formas simples que según ese autor está en la base de las formas artísticas. Para Jolles, las formas simples son:

aquellas formas que no se encuentran incluidas ni en la estilística, ni en la retórica, ni en la poética, ni tal vez en la "escritura". Las que, aunque pertenecen al arte, no llegan a ser obras de arte, las que, aunque poéticas, no son poemas, dicho brevemente aquellas formas que suelen designarse con los nombres de Hagiografía, Leyenda, Mito, Enigma, Sentencia, Casus, Memorabile, Marchen o Chiste (Jolles 1972: 16).

Para Jolles, estas formas están en la base de las obras artísticas, sólo que la historia literaria no las ha querido encontrar allí y, despreocupándose de ellas, las ha relegado al folklore o abandonado a otras disciplinas. Pues es justo en lo que tienen de folklore lo que de estas formas nos interesa; es decir, nos interesan por su función de formas culturales que, conllevando la imaginería de lo inconsciente, hacen visible en el arte los sustratos comunitarios que al mismo tiempo hacen posible el arte; en otras palabras, nos permiten ver, como diría la sociocrítica, el modo en que la socialidad del texto da pie a una poética y a una interpretación de la cultura de la que él es al mismo tiempo forma y agente.

Las formas simples de Jolles parecen coincidir con lo que posteriomente habría de llamarse formas o modalidades discursivas. Hay que recordar que estas propuestas de Jolles fueron concebidas en 1923, mucho antes de los trabajos de Foucault y mucho antes de que las ideas de Bajtín fueran conocidas o difundidas. Tomando eso en consideración, son sorprendentes ciertas similitudes con la metodología que Foucault describe en la Arqueología del saber (Foucault 1970), especialmente en el estudio que hace Jolles de la hagiografía en el que hay gestos teóricos sorprendentemente foucauldianos, como el siguiente: 


\begin{abstract}
Por consiguiente, el santo está ligado a la institución Iglesia. La pregunta ¿qué es el santo?, debido a que sólo a partir de este nexo tiene respuesta, se convierte en ¿cómo se llega a ser santo? Pregunta más amplia, más profunda y metodológicamente anterior, pregunta que no emerge de la persona, sino de la institución que reconoce al santo como tal (Jolles 1972: 31).
\end{abstract}

La relación entre conceptos, agentes, procesos e instituciones en la cita anterior, parece ya un presagio de la teoría del discurso, particularmente en la concepción de éste como práctica social. De esta forma, dejamos claro que la utilización de las ideas de Jolles, lejos de ser incompatibles con el marco teórico foucaldiano -el cual hemos venido usando en otros estudios de Magón-, le sirve más bien de complemento y confirmación.

Por otra parte, Foucault no sólo respalda ciertos principios filosóficos y éticos en nuestra metodología, como lo hemos aclarado en trabajos anteriores sino que además, técnicamente nos ofrece los instrumentos adecuados para el análisis de los contenidos culturales de las formas artísticas, es decir, la interdiscursividad y los aspectos ideosémicos del texto.

Para apreciar mejor la importancia del enigma como forma simple en "El clis de sol", se hace necesario un decurso teórico previo y básico para cualquier discusión posterior. Procederemos, pues, a definir las nociones básicas que utilizaremos.

\title{
Cultura e identidad: ontogénesis del sujeto
}

Para Edmond Cros, la cultura puede definirse (entre otras definiciones posibles) como un "espacio ideológico cuya función objetiva consiste en anclar una comunidad dentro de la conciencia que ella tiene de su identidad"(Cros 1995: 1. La traducción es nuestra). Por lo tanto, sus características básicas serían las siguientes:

1. Es específica: sólo existe porque se diferencia de otras.

2. Funciona como una memoria colectiva que sirve de referencia y es vivida oficialmente como custodia de continuidad y garante de la fidelidad que el sujeto colectivo debe guardar hacia la imagen que le ha sido dada de sí mismo.

3. Es de contornos fluctuantes que se rectifican sin cesar por nuevas coyunturas sociales o históricas que desembocan en refiguraciones fundamentales o en denegaciones.

Según Cros, la cultura es el lugar en que lo ideológico se ejerce más eficazmente ya que se basa en la problemática de la identificación. En relación con la identidad, el sujeto cultural constituye:

1. Una instancia de discurso investida por el yo.

2. El advenimiento y funcionamiento de una subjetividad.

3. Un sujeto colectivo.

4. Un proceso de sometimiento ideológico.

En otras palabras, el sujeto cultural es una identificación en que la subjetividad se aliena en una representación colectiva. 
Para terminar la referencia a los trabajos de Cros en este respecto, señalaremos las manifestaciones concretas de la cultura, la cual dista mucho de ser una idea abstracta ya que se revela en:

1. El lenguaje y sus diferentes prácticas discursivas.

2. El conjunto de instituciones y prácticas sociales.

3. La manera en que se reproduce en los sujetos.

Atendiendo a estas concreciones, todo estudio sobre la cultura o las identidades debe partir de esas manifestaciones o, al menos, tomarlas en consideración. En el estudio que nos ocupa, y muy particularmente, en el cuento que examinamos, hemos hecho revisión de las concreciones citadas ${ }^{2} y$, en este preciso momento, nos estamos ocupando de la tercera, es decir, de las formas de la interpelación cultural.

Como lo explicó claramente Louis Althusser, el sujeto adviene como tal por una instancia ideológica que lo antecede y lo interpela. Es de esta manera que el individuo deviene sujeto, aunque estrictamente hablando nunca se ha sido individuo.

Las investigaciones de Pecheux tienen el mérito de haber ligado, como lo señala Cros en un estudio anterior (Cros 1982: 47-60), la constitución del sentido (autoridad cultural) con la constitución del sujeto (identidać cultural); es decir, que Pecheux conecta la concreción uno con la concreción tres, a través del concepto de interpelación ideológica de Althusser. Cito el comentario de Cros al respecto:

Se conoce la tesis de este último (Althusser), sintetizada en una fórmula desde entonces célebre: "la ideología interpela a los individuos en sujetos". A justo título es que Pecheux insiste sobre la inadecuación de la fórmula individuo/sujeto y sobre la paradoja que ella implica de un sujeto llamado a la existencia. Pecheux observa con mucha agudeza que esta paradoja consiste en el hecho de que por un efecto retroactivo todo individuo es ya un sujeto; "el sujeto es de siempre un individuo interpelado en sujeto", sin duda porque todos los individuos reciben como evidente el sentido de lo que ellos entienden y dicen, leen y escriben...en tanto que sujetos hablantes, es decir, en fin de cuentas, para ceder a las sugerencia's de Althusser todavía, en tanto que forma-sujeto. Todo individ: io humano, es decir, social, sólo puede ser agente de una práctica si reviste la forma de sujeto. La "forma-sujeto" es en efecto, la forma de existencia histórica de todo individuo (Cros 1982: 53. La traducción es nuestra).

Aceptados esos matices, la siguiente pregunta se impone en este momento: ¿Cómo se constituye el individuo en sujeto de su discurso? A esa interrogante Pecheux responde: "Por el olvido de lo que lo determina, por el hecho de que él se identifica en tanto que forma sujeto con la formación discursiva que lo domina y se identifica con ésta reproduciendo en su propio discurso las huellas de lo que lo determina"(Cros 1982: 53. La traducción es nuestra). Lo determinante se encuentra en lo que la sociocrítica, siguiendo a Henri (Cros 1982: 54), denomina preconstruido o preasertado, lo cual es una construcción exterior y anterior al discurso, independiente con relación a lo que es construido en el enunciado. Continúa Cros:

Este preconstruido interpela al individuo en sujeto, pero éste se crea la ilusión de la autonomía retomando por su cuenta e integrando dentro de su discurso ese "más allá", ese siempre ya de antemano ahí que lo interpela; dicho de otro modo, es identificándose a ese más allá que él se identifica con él mismo (Cros 1982: 54. La traducción es nuestra). 
Pero identificarse a sí mismo es igualmente identificarse con los otros. En otras palabras, la coincidencia - dice Cros-, que es también connivencia, casi complicidad, entre Sujeto y Sí, se establece según la modalidad del "como si". Esta es precisamente la táctica de Magón, quien habla "como si" estuviera allí donde se le escucha y viceversa: como si el que lo escucha (el lector) estuviera allí donde él está.

Debemos recordar brevemente que el relato "El clis de sol" no se limita simplemente a contar una historia, sino que más bien propone un reto al lector, pues la historia que va a ser contada se le plantea como un problema por resolver. Lo que debe ser resuelto es la forma adecuada de interpretar la historia, de modo que esta interpretación permita sacar a luz la verdad de lo acontecido.

De modo que la historia se plantea más como enigma que como relato y por ello se impone una estructura dialógica en la que alguien interroga a otro. En la escena los actores son un narrador que apela directamente a su destinatario y le propone una cierta relación comunicativa; en esta relación comunicativa propuesta, el lector deberá limitarse a seguir las instrucciones del proponente, las cuales pueden sintetizarse del modo siguiente:

1. Se trata de un caso excepcional (maravilla)

2. Debe someterse a juicio.

3. Observarse y analizarse.

4. Y ofrecer un veredicto.

5. Para cotejarse luego con el análisis del propio narrador.

6. En conclusión: el lector está siendo sometido a una prueba.

Es precisamente en este punto en el que la identificación del Sí depende de la identificación con el otro (el narrador Magón) y en el que identificación es sinónimo de coincidencia y coincidencia lo es de connivencia y complicidad; es justamente en este punto en que la forma simple del enigma se inserta como modelo explicativo de la realización en lengua del efecto identificatorio mostrando sus dos esenciales caracterizaciones: el modo impositivo de la identificación y la misión interpretativa que supone.

El enigma es una pregunta que exige respuesta. Según Jolles, en el enigma el hombre que sabe interroga a otro, pero formula la pregunta de modo que obliga al otro a saber. Ese es el caso entre el narrador de Magón y su lector; de ahí que éste quede compelido a involucrarse en el texto. Así explica Jolles la relación entre uno y otro en el enigma:

Uno está en posesión del saber; es, como persona, el conocedor, el sabio. Frente a él se halla una segunda persona que, inducida por la pregunta, pone de su parte toda su fuerza y vida para alcanzar también la posesión de aquel saber y mostrarse al otro como sabio (Jolles 1972: 120).

El enigma es, según Jolles: "una pregunta condicionada por el saber y que pone al saber como condición” (Jolles 1972: 121). La forma en que Magón obliga al lector a saber es precisamente mediante la apelación de "sabios", lo cual indica que el saber que se busca ya existe y está en aquel que debe contestar. El signo del enigma no es, pues, el de la libertad, sino el de la subordinación. De ahí que siendo "El Clis de sol" un enigma, es entonces un texto que compromete, que se impone y subordina. 
¿Cuál es el fin de los enigmas? Para responder a esta pregunta es necesario contestar a otra previa: ¿Por qué pregunta el que interroga si ya conoce la respuesta? Porque lo que le interesa no es escuchar nuevamente la respuesta, sino averiguar si el interrogado está en condiciones de dar la respuesta; en otras palabras, se trata de investigar si el interrogado posee cierta dignidad. En el caso del cuento de Magón, se trata de averiguar si se "es digno" del apelativo de "sabio" que el narrador confiere al lector. Se trata de examinar el ingenio del que adivina.

"El Clis de Sol" parte de la forma enigma y de ahí que sea un texto que interroga. El fin de la enigmación es, pues, hacer un examen de igualdad de saber entre el que formula la pregunta y el que la descifra. Pero las teorías de Jolles van más lejos en su asombrosa equivalencia con el texto de Magón. Según Jolles, el que formula el enigma - el sabio- no está solo, sino que representa a un grupo unido precisamente por ese saber. De este modo, el interrogado pretende demostrar que él es parte de ese grupo porque él también posee ese saber. Como se observa, se trata de una idea del saber como posesión, noción que refuerza el debate mencionado sobre la educación en el siglo XIX y muy particularmente según las reformas políticas del momento.

La solución al enigma -que en el caso de "El Clis de Sol" jamás se enuncia, queda en reserva-, es una especie de consigna o santo y seña que proporciona la entrada al círculo cerrado. La introducción a ese círculo o grupo es una cuestión vital, tanto para el que pretende entrar como para el que concede la entrada, ya que la existencia de ese todo cerrado que es la comunidad cultural en este caso, depende de que sea colectivamente compartida. Por tanto, lo que se enigma es lo consabido, lo sabido por los dos. Lo que se enigma es entonces, como dice Jolles, precisamente "el secreto de la alianza". De ahí que lo que se enigma se encuentra determinado por el sentido del círculo cerrado. El secreto de esta alianza es aquello que funda la comunidad ideológica del grupo y que, sin embargo es indefinible, indecible, como un ideologema ${ }^{3}$, afectado como está por el misterio, por el sentido de lo impenetrable. En el enigma, como en la adivinación, se procede metafóricamente por elusión. Por eso, el enigma representa por antonomasia el saber como poder, relación que hemos demostrado tanto en nuestro examen de "El principio de autoridad" como en el de "El Clis de sol".

Si la forma interpelativa se da gracias al "secreto de la alianza", el agente de la identificación será precisamente el sujeto cultural; así lo afirma Cros en su libro D’un sujet a l'autre (1995). En consecuencia, para Cros la cultura es una realidad primera y ella es la que interpela como sujeto. El sujeto cultural es, pues, una metamorfosis del sujeto ideológico y es interiorizado en el momento de la formación del sujeto, de la subjetividad. Pero si bien el sujeto cultural es una instancia de cohesión que subsume a todos los individuos en una colectividad, Cros advierte que lo hace al mismo tiempo que remite a cada uno a su posición de clase, ya que cada una de esas clases se apropia de ese bien colectivo de manera diferente (Cros 1995). El sujeto cultural es, entonces, un mecanismo de inclusión/exclusión y eso fue justamente lo que observamos en "El clis de sol": las formas de la interpelación y un proceso conflictivo de identificación en dos niveles: en el de los sujeto-soporte y en el de los enunciados. A saber:

1. En el nivel de la doble función de la identificación: incluir/excluir, por medio de la cual se ancla al individuo a una comunidad pero remitiéndolo al mismo tiempo a su posición de clase.

2. En el nivel del asertado, en el que se pone en conflicto una emblemática que precisamente en el momento en que surge este texto se está intentando consolidar como imagen nacional del sujeto cultural. 
"El clis de sol" le propone, pues, al lector un problema por resolver. Lo que debe ser resuelto es la forma adecuada de interpretar la historia que el cuento relata a través de una secuencia de preguntas y respuestas. Pero no hay modo de interpretar sin recurrir a la autoridad cultural, ya que ella es el sentido y la significación, y el "hombre sabio" es el depositario de ese sentido y de esa significación. Si toda interpretación legítima se identifica con la ley de la cultura y el "hombre sabio" es su depositario, el lector de "El clis de sol" no tiene más alternativa que identificarse con la sabiduría de su narrador quien, cual Esfinge, lo interroga y lo amenaza en la frontera misma de una comunidad imaginada.

Identidad es, pues, consenso en la interpretación, aunque este consenso no sea más que una utopía, innombrable e inubicable, localizable únicamente en la "reserva" de este cuento que, por eso mismo, se propone al lector como un enigma.

\section{Notas}

1. Ver la bibliografía respectiva al final de esta publicación.

2. Ver en la bibliografía los artículos publicados por parte de la autora en relación con este cuento.

3. Para no entrar en una nueva digresión teórica, respetuosamente invitamos al lector a leer el desarrollo de esta noción en nuestro artículo "Sobre identidades y nacionalismos. (Contrastes epistemológicos y metodológicos)". Revista de Filología y Lingüística. XXV (1), 1999.

\section{Bibliografía}

Amoretti Hurtado, María. 1998. "Autor y autoridad...cuestión de principios". Káñina. XXII (1).

1998. "Dos vivazos y un tonto en un certamen de mentiras". Káñina. XXII (2).

1997. "Propuestas metodológicas para una lectura diferente de los textos de Magón". Káñina. XXI (2).

Cros, Edmond. 1995. D'un sujet a l'autre: Sociocritique et Psychanalyse. Montpellier.

1982-1. "Pratiques et formations discursives". Fonctionnements textuels. Imprévue. Montpellier, 47-60.

Foucault, Michel. 1970. Arqueología del saber. México: Siglo XXI.

Jolles, Andrés. 1972. Las formas simples. Chile: Editorial Universitaria. 